\title{
Isothermal approach to assemble spatial DNA nanotubes for drug delivery
}

\author{
Xiaolong Shi ${ }^{1}$, Haiyan Zhao ${ }^{1}$, Xin Li $^{2}$ and Tao Song ${ }^{3,4}$ \\ ${ }^{1}$ Key Laboratory of Image Information Processing and Intelligent Control, School of Automation, Huazhong University of \\ Science and Technology, Wuhan 430074, Hubei, China \\ ${ }^{2}$ Department of Gynecology 2, Renmin Hospital of Wuhan University, Wuhan 430060, Hubei, China \\ ${ }^{3}$ College of Computer and Communication Engineering, China University of Petroleum, Qingdao 266580, Shandong, China \\ ${ }^{4}$ Departamento de Inteligencia Artificial, Universidad Politécnica de Madrid, Campus de Montegancedo, Boadilla del Monte \\ 28660, Madrid, Spain
}

Correspondence to: Tao Song, email: tsong@upc.edu.cnt.song@upm.es

Keywords: DNA nanotechnology; DNA origami; DNA nanotube; drug cargo

Received: October 09, 2017

Accepted: November 13, 2017

Published: January 04, 2018

Copyright: Shi et al. This is an open-access article distributed under the terms of the Creative Commons Attribution License 3.0 (CC BY 3.0), which permits unrestricted use, distribution, and reproduction in any medium, provided the original author and source are credited.

\section{ABSTRACT}

DNA Nanostructures assembled from artificial single stranded DNA provided an engineering method to fabricate highly biocompatible spatial objects, which have potentials applications as drug delivery vehicles and templates for the patterning of biological molecules as biosensor for active hepatic targeting drug delivery. Most DNA nanostructures are constructed by annealing process, which means some thermal sensitive drugs and biosensors made from peptides or proteins in the structure will be denatured during fabrication. Fabrication of DNA nanostructure under isothermal condition remains challenging. Herein we report a simple and cost-effective method to form DNA nanotubes in the presence of urea with only two single-stranded tiles (SST) at room temperature. The constructed DNA nanotubes were observed and analyzed by atomic force microscopy (AFM). Experimental results show the feasibility and stability of our method. This method avoids traditional annealing procedure and will provide possibility to further assembly nano-scale structures in vivo.

\section{INTRODUCTION}

DNA, known as genetic materials for replication and storage of information in biology, is also an ideal material for building up nanostructures due to the precisely predicted behavior according to the WatsonCrick base pairing rules. A collection of one-, two- and three-dimensional DNA nanostructures have been formed [1-9]. Among these nanostructures, the DNA nanotubes are promising ones which can be applied as drug delivery vehicles, functional elements in nano-devices and programmable templates for the organization of materials and biomolecules [10].

Several strategies have been used to construct DNA nanotubes. These methods include DNA origami [11-14], DNA tile self-assembly [1, 3, 15-18] and SST (single-stranded tile) $[7,10,19,20]$. These approaches use thermal annealing protocol in which component strands were mixed in a magnesium-containing buffer followed by annealing from high temperature (e.g., $\sim 95^{\circ} \mathrm{C}$ ) to room temperature. However when DNA nanotubes are used as templates for patterning materials, it is desirable to form the nanostructure under isothermal conditions especially at room temperature, for some functional molecules such as proteins are thermally sensitive and will denature at high temperature (streptavidin, $75^{\circ} \mathrm{C}$ ).

Several efforts have been made to realize isothermally DNA self-assembly of nanostructures. Jungmann et al. achieved isothermal assembly of DNA origami by alerting the concentration of formamide at room temperature [21]. This method had the experimental limitation of setup up of dialysis system and failed to construct DNA nanotubes using a single self-complementary sequence. Gothelf et al. applied denature agents such as formamide and urea to assemble various complex DNA structures at room temperature by controlling the concentration of the chemical 
[22]. This method is simple and efficient which requires no thermal cycler or dialyzer. But the nanostructures formed consume a large amount of strands which lead to high cost. Andreas Kopielski and co-workers introduced betaine to achieve 2D DNA rectangle-shaped origami at room temperature [23]. Yin and co-workers achieved a DNA isothermal-assembly system in which the melting temperature of the component strands were precisely controlled [24]. To achieve the required temperature, the sequences of the strands must be designed cautiously and take GC content, domain length, and assembly buffer into consideration. This method can be used at a wide range of temperature isothermally but has the limitation of requiring facile design of DNA sequence to obtain the corresponding temperature. Winfree and co-workers successfully formed DNA nanotubes with micrometers-scale length from DX tiles at room temperature [25]. They first formed the incomplete tile using conventional thermal denature procedure and then made use of strand displacement reactions to construct DNA nanotubes. This method still includes thermal annealing during the whole process. Mao, C. D. and co-workers constructed ladder-like and ring-like DNA nanostructures through the two synchronous selfassembly processes under isothermal conditions [26]. But the method works under the hypothesis that when brought into proximity in space the two independent assembly processes could be synchronized and would display high collaboration. There are some recently published results on DNA nanotubes, see e.g. in [27-30].

Unlike multi-stranded tile self-assembly with rigid core, the tile of SST-based self-assembly is single-stranded DNA (ssDNA) that is composed entirely of concatenated sticky ends. The SSTs work cooperatively with unpurified strands without the need of precise control of their stoichiometric quantity like DNA origami. But the method requires no scaffold compared to DNA origami. The nanostructures constructed using SST-based method holds great promise in applications ranging from electronics to nanotechnology, they can be applied as nanowires and templates for organization of functional elements.

Herein, we report a simple and cost-effective method for assembling DNA nanotubes based on SST without prior thermal annealing process using only two synthetic DNA strands that contain 42 bases, respectively. In this approach urea is introduced to realize the assembly process at room temperature. The DNA nanotubes with variable diameter and length of several hundred nm were observed under AFM after mixing the two strands with the same concentration in urea-containing assembly buffer and incubation at room temperature. Therefore the approach enables a simple and low cost technique for DNA tube construction in a one-pot solution. There are several results on assembling DNA nano tubes by SSTs with different sizes, but the purpose or potential application for drug delivering in this work is novel.

\section{DESIGN}

In our method, two SST motifs labeled S1 and VS1 are used to synthesize DNA nanotubes. The two SST strands S1 and VS1 are designed by software NUPACK for analysis and design of nucleic acid structures, devices, and systems. The SSTs strands designed have well thermodynamic stability. Each SST motif is a 42-base oligonucleotide composed of 4 consecutive modular domains (represented by colored line segments, as shown in Figure 1) which are

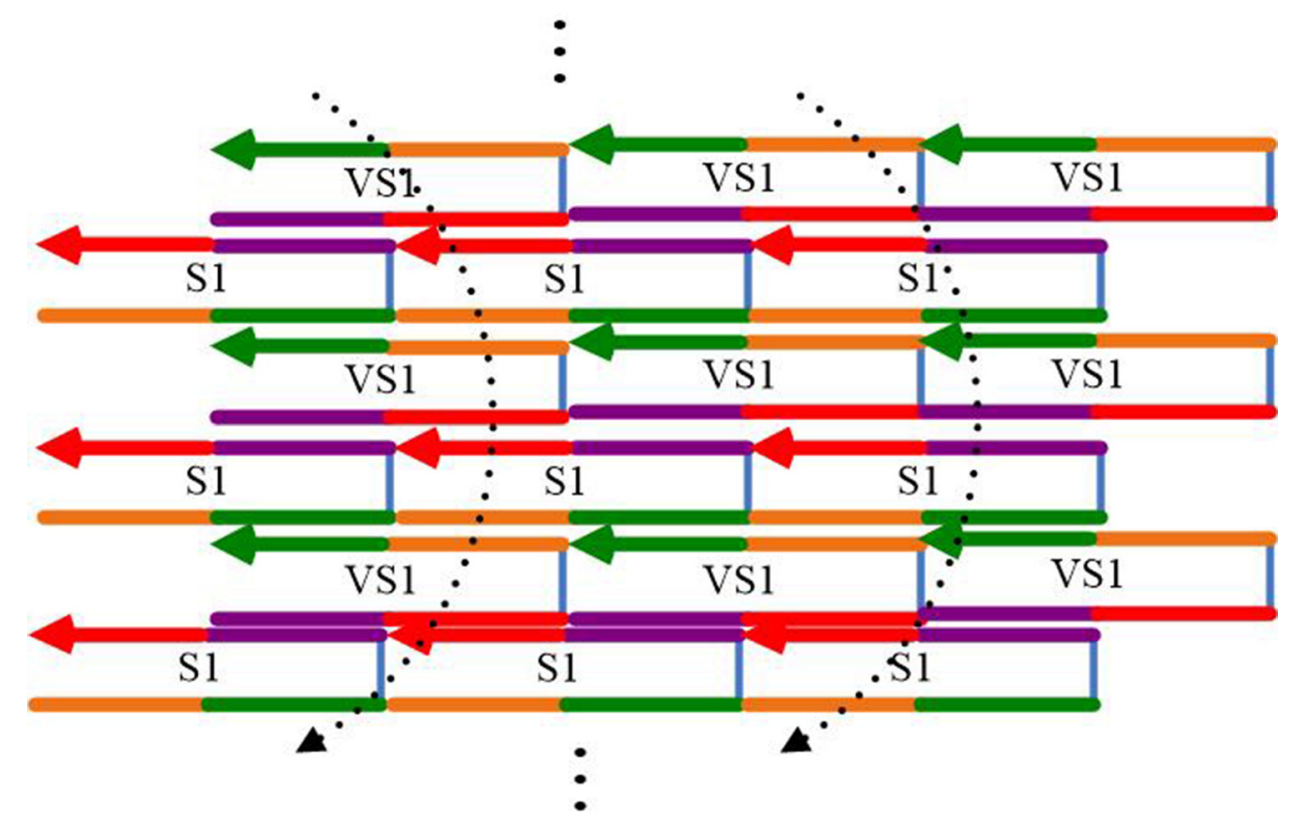

Figure 1: Schematic illustration of DNA Nanotubes from 2 SST. S1, VS1, where colored lines represent modular domains. The domains with the same color are complementary. 
$10,11,10$, and 11 bases long respectively. In the SST motif shown in Figure 1, domains with the odd number (domains 1 and 3) are complementary and the even-numbered domains (domains 2 and 4) bind together according to the Watson-Crick base pairing principle to form double DNA strands, i.e. the following pairs of domains are fully complementary: domain 1 of $\mathrm{S} 1$ and domain 3 of VS1, domain 2 of S1 and domain 4 of VS1, domain 3 of $\mathrm{S} 1$ and domain 1 of $\mathrm{VS} 1$, domain 4 of $\mathrm{S} 1$ and domain 2 of VS1. With the interaction of complementary domains of the two SST motifs a helix structure is formed. Every helix is composed of large amounts of segments spaced by 21-nucleotide-length (two turns) long dsDNA along the axis. Through repeating tiling of the same dsDNA segments the tubes are formed.

\section{RESULTS}

The SST strands S1 and VS1 were purchased from Shanghai Sangon Biotech with PAGE purification in dry form. Before use the strands were dissolved in $1 \times \mathrm{TAE}$ buffer(17.5 mM $\mathrm{Mg}^{2+}, 20 \mathrm{mM}$ Tris with pH 7.6, $2 \mathrm{mM}$ EDTA) $(100 \mu \mathrm{M})$ by hand.

The two strands S1 and VS1 were mixed with a final concentration of $1 \mathrm{uM}$ per strand in assembly buffer 1×TAE $\left(20 \mathrm{mM} \mathrm{Mg}{ }^{2+}, 20 \mathrm{mM}\right.$ Tris with $\mathrm{pH} 7.6,2 \mathrm{mM}$ EDTA) containing $6 \mathrm{M}$ urea, and then the mixture was subjected to incubation process at room temperature $\left(21^{\circ} \mathrm{C}\right)$ for a time period.

AFM was performed using Bruker Multimode 8 with fluid-scanasyst mode and scanasyst-fluid+ tip. A drop of $3 \mu \mathrm{l}$ sample solution was pipetted onto a freshly cleaved mica surface and left to adsorb for 2 minutes. Two portions of $20 \mu \mathrm{l}$ buffer were added onto the mica and AFM tip, respectively. AFM images were obtained after adjusting parameters.

Before being examined by AFM the sample were incubated at room temperature $\left(21^{\circ} \mathrm{C}\right)$ for 24 hours. Direct imaging of the nanostructures by AFM provided the experiment evidence of tubular morphology which can be conclude from the height variation curve of the structure (Figure 2). According to the AFM image, the DNA nanotube is up to $460 \mathrm{~mm}$ long and around $7 \mathrm{~nm}$ high with a $\sim 110 \mathrm{~nm}$ width.

Several tubular shapes with variable length and diameter could be observed obviously, as can be seen in Figure 3 which may attribute to the random curve during the repeating assembling of the two strands.

In order to test the effect of the method, we prepared two samples one of which was the mixture of the two strands with urea and the other without urea. The concentration and stoichiometry of two strands applied were the same. The buffer was also the same except that no urea was added to the second sample, i.e. the difference between the first and the second sample was whether to include the urea. The sample was scanned by AFM after incubation at $21^{\circ} \mathrm{C}$ overnight. In Figure 4, it shows the AFM images of the two samples with $10 \mathrm{um} \times 10 \mathrm{um}$ scanning size, where the data height range is $-10 \mathrm{~nm}$ to 10 $\mathrm{nm}$. In the left part of Figure 4 (with urea), the nanotubes could be observed obviously by AFM. The nanotubes have variable length ranging from $100 \mathrm{~nm}$ to $800 \mathrm{~nm}$. No DNA

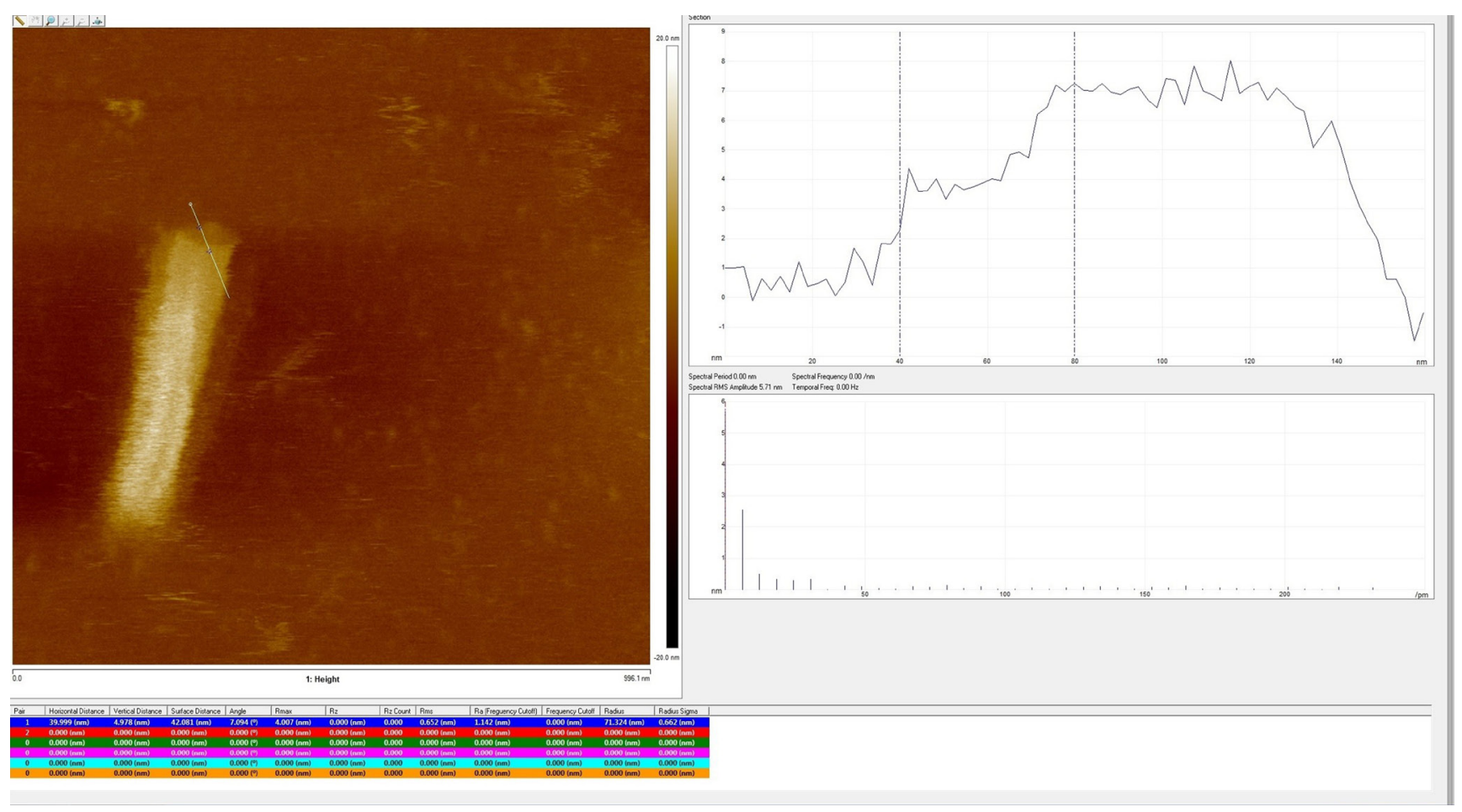

Figure 2: AFM image of the nanotube by room temperature urea incubation which shows tubular structure. 
nanotube can be observed in the right part of Figure 4 (without urea). It can be concluded with a big probability that DNA nanotubes can not be synthesized under the circumstance without urea. The result showed the effect of urea which can decrease the melting temperature down to room temperature at appropriate concentration. Urea as a non-toxic chemical additive enables to assemble nanostructures at room temperature. Therefore, it is indispensable for the interaction of the two strands to curve into nanotubes.

In order to check the stability of the assembled nanotubes, we incubated the samples with urea for several days. In Figure 5, it shows the nanostructures assembled from $\mathrm{S} 1$ and VS1 as time elapsed. After being stored at room temperature for more than one month, DNA nanotubes remained intact as shown by AFM imaging.

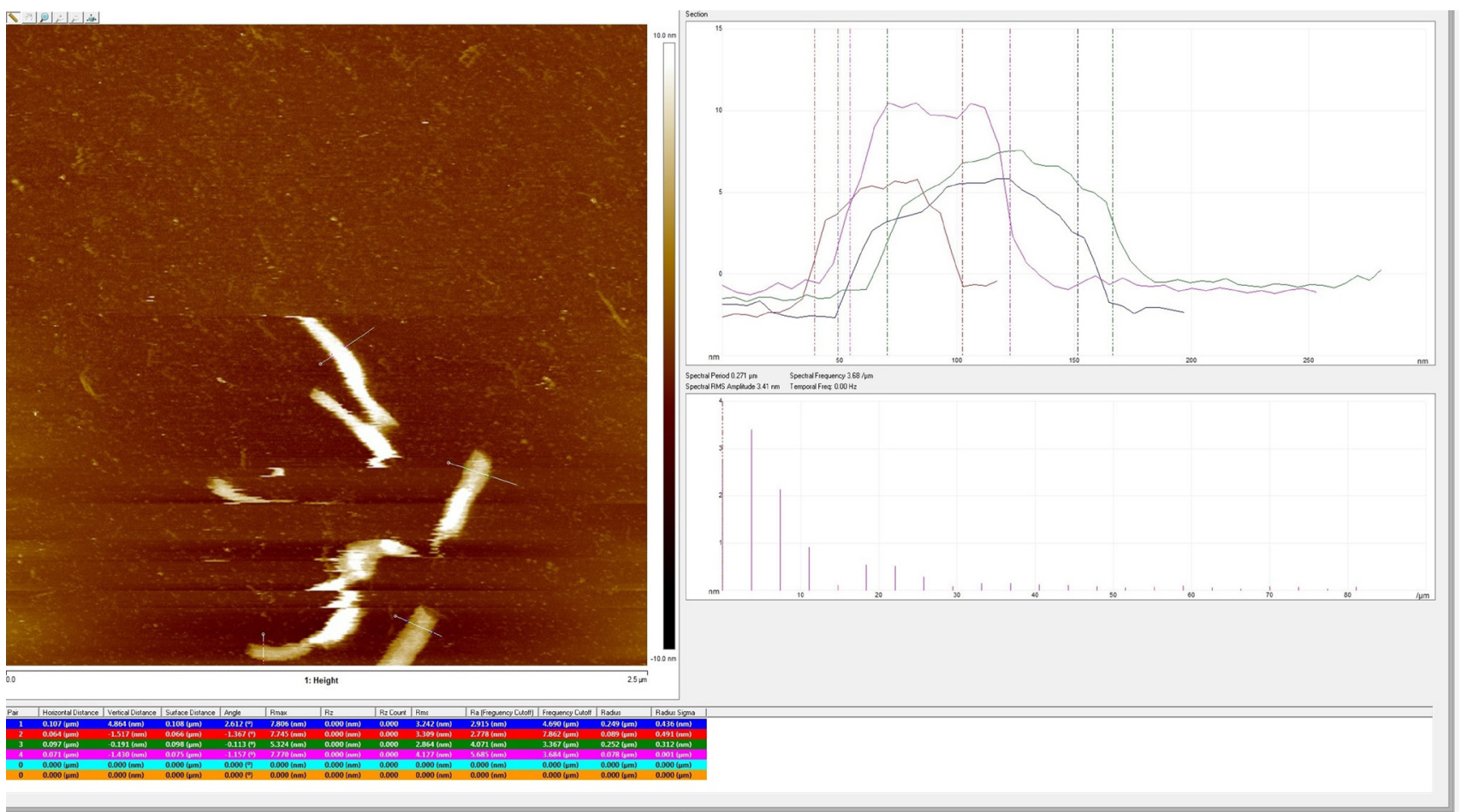

Figure 3: AFM image of the nanotubes by room temperature urea incubation that displays variable length and diameter.
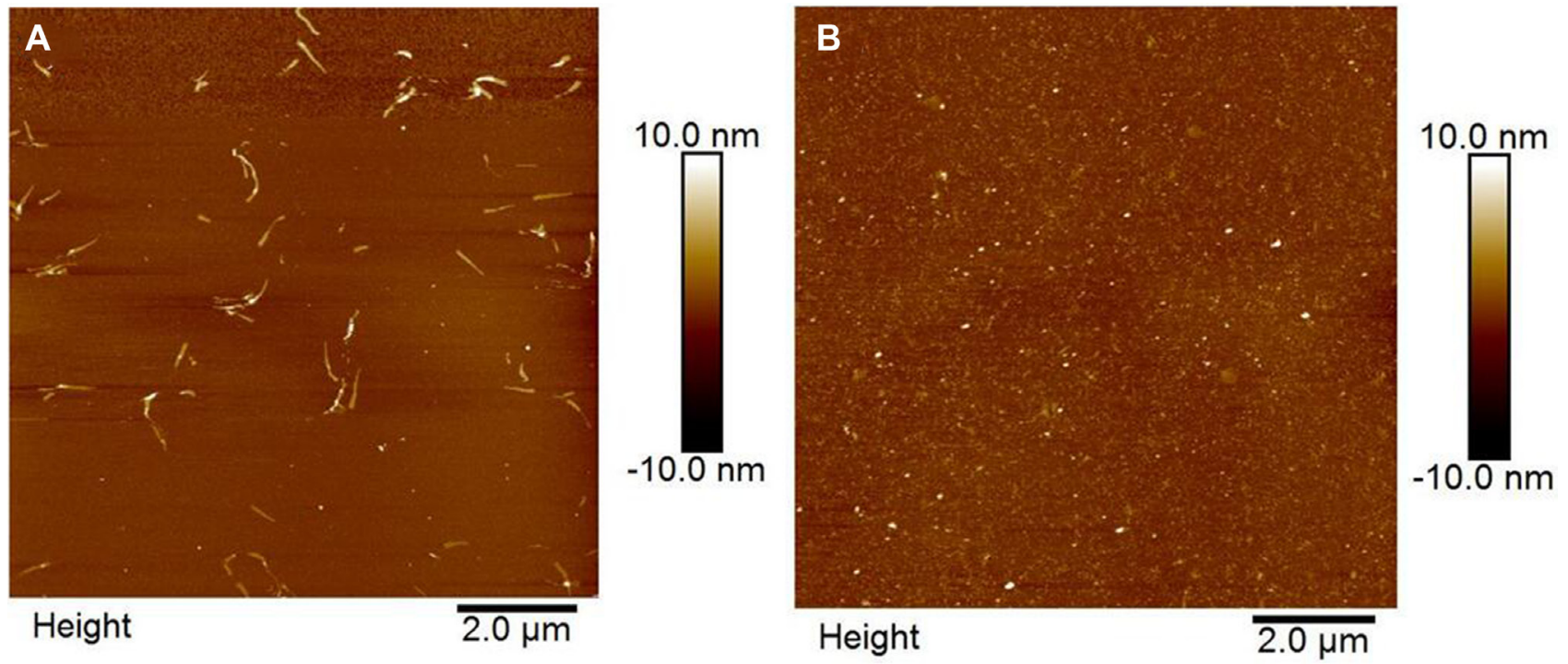

Figure 4: AFM image of the samples by room temperature incubation with and without urea for overnight. 
The stability may attribute to the long single-stranded overhangs, which ensure strong cohesions between the strands. Experiment results further confirms the stability and robustness of the method.

\section{CONCLUSION AND FINAL REMARKS}

In this work, we present a method to form DNA nanotubes at room temperature using only 2 different synthesized DNA strands each of which contain 42 bases. This approach is simple and cost-effective for largescale application. After incubation of the mixture of the two strands in urea-containing assembly buffer at room temperature, we observed DNA nanotubes with variable diameter and length of several hundred nm under AFM. After incubation for more than 1 month DNA nanotubes
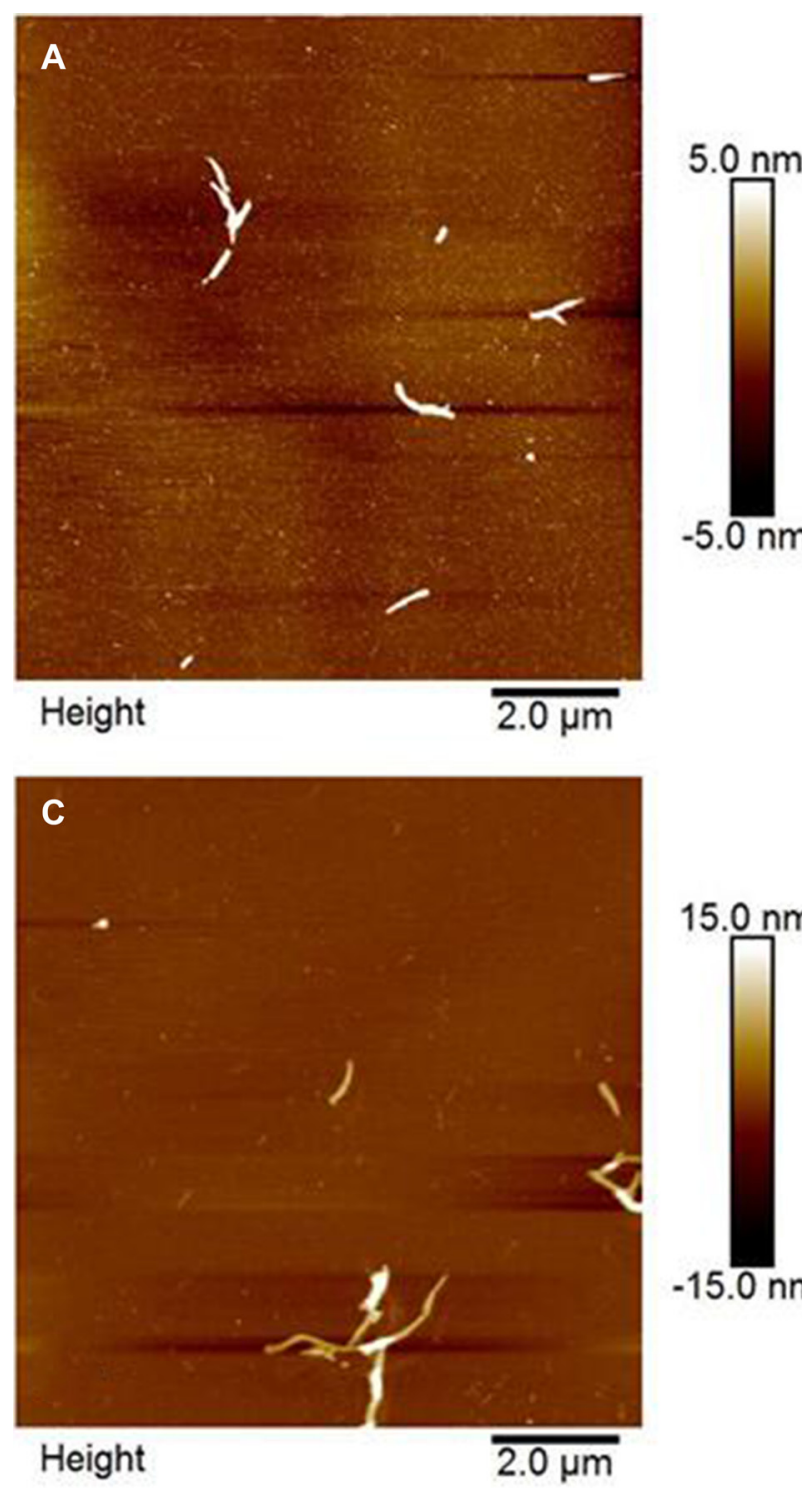

were also observed. Experimental results show the feasibility and stability of our method.

In conclusion, we have fabricated DNA nanotubes with low cost in the presence of urea that avoid heating at room temperature. The tubes formed here hold great potential in applications ranging from electronics to nanotechnology. They are likely to be applied as drug delivery tools and templates for the nanoscale assembly of temperature-sensitive proteins and other functional components.

The further research is to seek ways to control the size of the nanotubes under isothermal condition according to the size of the cargo for many promising applications, especially for in vivo drug-delivery. There are some other bio-inspired computing models, such as neural networks [31-37], would do a favor in some sense for optimizing the structure of DNA nanotubes.
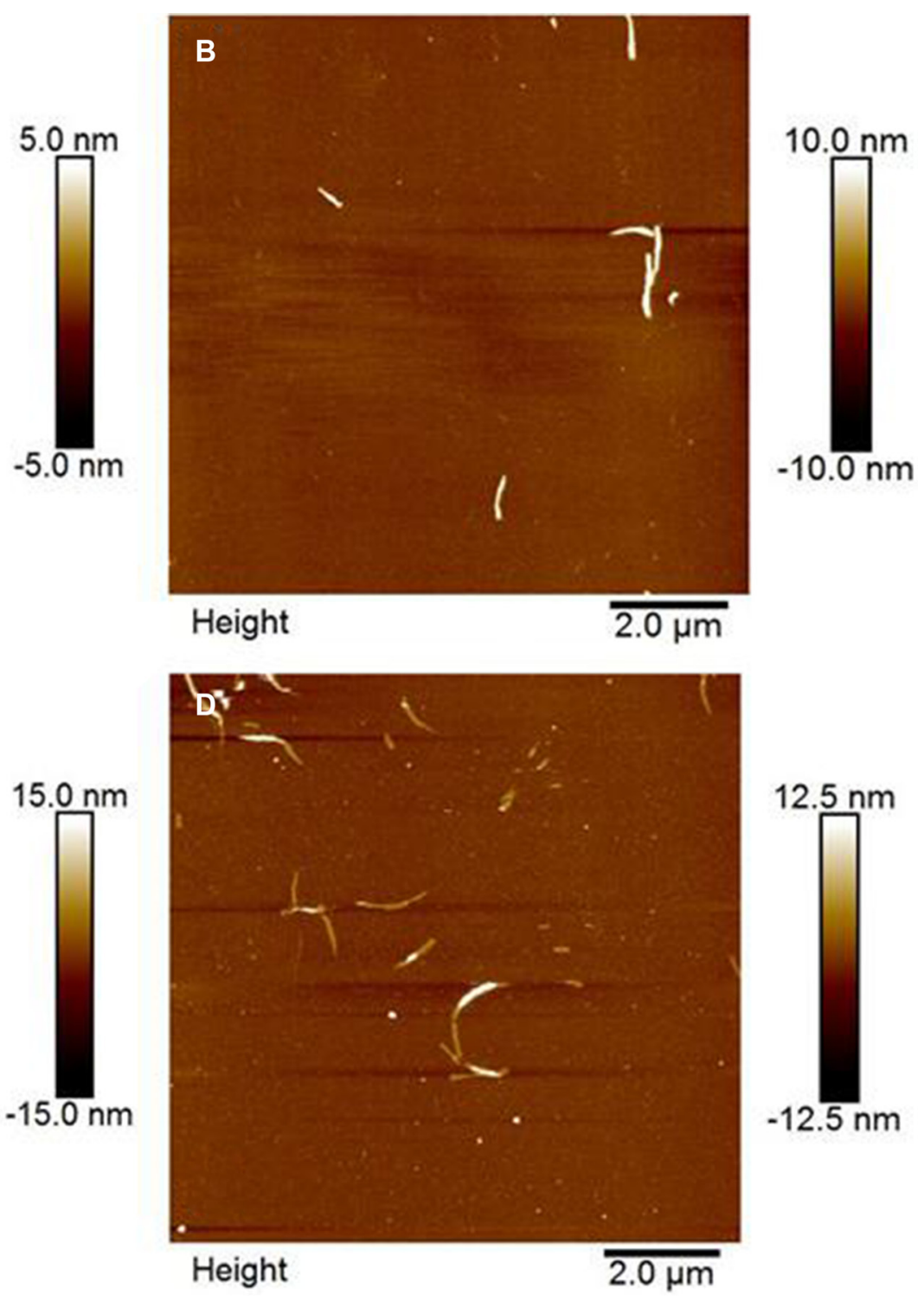

Figure 5: AFM image of the nanotubes by SSTs S1 and VS1 with urea as time elapsed. (A) The sample was kept at $21^{\circ} \mathrm{C}$ for 2 days. (B) Samples observed after incubation at $21^{\circ} \mathrm{C}$ for 3 days. (B) Samples incubated at $21^{\circ} \mathrm{C}$ for more than 5 days. (D) Samples incubated at room temperature for more than 1 month. 


\section{ACKNOWLEDGMENTS AND FUNDING}

Xiaolong Shi was supported by the National Natural Science Foundation of China (61572213, 61772376), Tao Song was supported by Research Project TIN2016-81079R(AEI/FEDER, Spain-EU) and grant 2016-T2/TIC-2024 from Talento-Comunidad de Madrid, Key Research and Development Program of Shandong Province (No. 2017GGX10147). Xun Wang was supported by National Natural Science Foundation of China (61502535 and 61672248). Xin Li was supported by National Natural Science Foundation of China $(61272071,61672248)$, Natural Science Foundation of Hubei Province (2014CFB730).

\section{CONFLICTS OF INTEREST}

All authors have no conflicts of interest.

\section{REFERENCES}

1. Yan H, Park SH, Finkelstein G, Reif JH, LaBean TH. DNA-templated self-assembly of protein arrays and highly conductive nanowires. Science. 2003; 301:1882-84.

2. Ding B, Sha R, Seeman NC. Pseudohexagonal 2D DNA crystals from double crossover cohesion. J Am Chem Soc. 2004; 126:10230-31.

3. Liu D, Park SH, Reif JH, LaBean TH. DNA nanotubes self-assembled from triple-crossover tiles as templates for conductive nanowires. Proc Natl Acad Sci USA. 2004; 101:717-22.

4. He Y, Chen Y, Liu H, Ribbe AE, Mao C. Self-assembly of hexagonal DNA two-dimensional (2D) arrays. J Am Chem Soc. 2005; 127:12202-03.

5. Malo J, Mitchell JC, Vénien-Bryan C, Harris JR, Wille H, Sherratt DJ, Turberfield AJ. Engineering a 2D protein-DNA crystal. Angew Chem Int Ed Engl. 2005; 44:3057-61.

6. Park SH, Barish R, Li H, Reif JH, Finkelstein G, Yan H, Labean TH. Three-helix bundle DNA tiles self-assemble into 2D lattice or 1D templates for silver nanowires. Nano Lett. 2005; 5:693-96.

7. Yin P, Hariadi RF, Sahu S, Choi HM, Park SH, Labean TH, Reif JH. Programming DNA tube circumferences. Science. 2008; 321:824-26.

8. Hamada S, Murata S. Substrate-Assisted Assembly of Interconnected Single-Duplex DNA Nanostructures. Angew Chem. 2009; 121:6952-55.

9. Zheng J, Birktoft JJ, Chen Y, Wang T, Sha R, Constantinou PE, Ginell SL, Mao C, Seeman NC. From molecular to macroscopic via the rational design of a self-assembled 3D DNA crystal. Nature. 2009; 461:74-77.

10. Wilner OI, Orbach R, Henning A, Teller C, Yehezkeli O, Mertig M, Harries D, Willner I. Self-assembly of DNA nanotubes with controllable diameters. Nat Commun. 2011; 2:540.
11. Mousavi-Khattat M, Rafati A. Gill P. Fabrication of DNA nanotubes using origami-based nanostructures with sticky ends. Journal of Nanostructure in Chemistry. 2015; 5:177-83.

12. Fu Y, Zeng D, Chao J, Jin Y, Zhang Z, Liu H, Li D, Ma H, Huang Q, Gothelf KV, Fan C. Single-step rapid assembly of DNA origami nanostructures for addressable nanoscale bioreactors. J Am Chem Soc. 2013; 135:696-702.

13. Douglas SM, Chou JJ, Shih WM. DNA-nanotube-induced alignment of membrane proteins for NMR structure determination. Proc Natl Acad Sci USA. 2007; 104:6644-48.

14. Rothemund PW. Folding DNA to create nanoscale shapes and patterns. Nature. 2006; 440:297-302.

15. Mohammed AM, Schulman R. Directing self-assembly of DNA nanotubes using programmable seeds. Nano Lett. 2013; 13:4006-13.

16. Ke Y, Liu Y, Zhang J, Yan H. A study of DNA tube formation mechanisms using 4-, 8-, and 12-helix DNA nanostructures. J Am Chem Soc. 2006; 128:4414-21.

17. Liu H, Chen Y, He Y, Ribbe AE, Mao C. Approaching the limit: can one DNA oligonucleotide assemble into large nanostructures? Angew Chem Int Ed Engl. 2006; 45:1942-45.

18. Rothemund PW, Ekani-Nkodo A, Papadakis N, Kumar A, Fygenson DK, Winfree E. Design and characterization of programmable DNA nanotubes. J Am Chem Soc. 2004; 126:16344-52.

19. Rahbani JF, Hariri AA, Cosa G, Sleiman HF. Dynamic DNA Nanotubes: Reversible Switching between Single and Double-Stranded Forms, and Effect of Base Deletions. ACS Nano. 2015; 9:11898-908.

20. Kim J, Ha TH, Park SH. Substrate-assisted 2D DNA lattices and algorithmic lattices from single-stranded tiles. Nanoscale. 2015; 7:12336-42.

21. Jungmann R, Liedl T, Sobey TL, Shih W, Simmel FC. Isothermal assembly of DNA origami structures using denaturing agents. J Am Chem Soc. 2008; 130:10062-63.

22. Zhang Z, Song J, Besenbacher F, Dong M, Gothelf KV. Self-assembly of DNA origami and single-stranded tile structures at room temperature. Angew Chem Int Ed Engl. 2013; 52:9219-23.

23. Kopielski A, Schneider A, Csáki A, Fritzsche W. Isothermal DNA origami folding: avoiding denaturing conditions for one-pot, hybrid-component annealing. Nanoscale. 2015; 7:2102-06.

24. Myhrvold C, Dai M, Silver PA, Yin P. Isothermal selfassembly of complex DNA structures under diverse and biocompatible conditions. Nano Lett. 2013; 13:4242-48.

25. Zhang DY, Hariadi RF, Choi HM, Winfree E. Integrating DNA strand-displacement circuitry with DNA tile selfassembly. Nat Commun. 2013; 4:1965.

26. Nie Z, Wang P, Tian C, Mao C. Synchronization of two assembly processes to build responsive DNA nanostructures. Angew Chem Int Ed. 2014; 53:8402-05.

27. Shi X, Wang Z, Deng C, Song T, Pan L, Chen Z. A novel bio-sensor based on DNA strand displacement. PLoS One. 2014; 9:e108856. 
28. Shi X, Wu X, Song T, Li X. Construction of DNA nanotubes with controllable diameters and patterns using hierarchical DNA sub-tiles. Nanoscale. 2016; 8:14785-92.

29. Shi X, Chen C, Li X, Song T, Chen Z, Zhang Z, Wang Y. Size-controllable DNA nanoribbons assembled from three types of reusable brick single-strand DNA tiles. Soft Matter. 2015; 11:8484-92.

30. Li X, Hong L, Song T, Rodríguez-Patón A, Chen C, Zhao H, Shi X. Highly biocompatible drug-delivery systems based on DNA nanotechnology. J Biomed Nanotechnol. 2017; 13:747-57.

31. Li X, Song T, Chen Z, Shi X. A universal fast colorimetric method for DNA signal detection with DNA strand displacement and gold nanoparticles. J Nanomater. 2015; 407184.

32. Chen Z, Song T, Huang Y., Shi X., Solving vertex cover problem using DNA tile assembly model. J Appl Math. 2013; 407816.
33. Wang X, Song T, Gong F, Zheng P. On the computational power of spiking neural $\mathrm{P}$ systems with self-organization. Sci Rep. 2016; 6:27624.

34. Song T, Gong F, Liu X, Zhao Y, Zhang X. Spiking neural $\mathrm{P}$ systems with white hole neurons. IEEE Trans Nanobioscience. 2016; 15:666-73.

35. Song T, Pan Z, Wong DM, Wang X, Design of logic gates using spiking neural P systems with homogeneous neurons and astrocytes-like control. Inf Sci. 2016; 372:380-91.

36. Beneš D, Rodríguez-Patón A, Sosík P. Directed evolution of biocircuits using conjugative plasmids and CRISPRCas9: design and in silico experiments. Nat Comput. 2017; 16:497-505.

37. Rodríguez-Patón A, Sainz de Murieta I, Sosík P. DNA strand displacement system running logic programs. Biosystems. 2014; 115:5-12. 